\title{
Leucocephalon yuwonoi (McCord, Iverson, and Boeadi 1995) - Sulawesi Forest Turtle, Kura-Kura Sulawesi
}

\section{Cris Hagen ${ }^{1}$, Steven G. Platt ${ }^{2}$, and Charles J. Innis ${ }^{3}$}

\author{
${ }^{1}$ Savannah River Ecology Laboratory, Drawer E, Aiken, South Carolina 29802 USA [hagen@srel.edu]; \\ ${ }^{2}$ Department of Biology, Box C-64, Sul Ross State University, Alpine, Texas 79832 USA [splatt@sulross.edu]; \\ ${ }^{3}$ New England Aquarium, Central Wharf,Boston, Massachusetts02110USA [cinnis@neaq.org]
}

Summary. - The Sulawesi forest turtle, Leucocephalon yuwonoi (Family Geoemydidae), is one of the world's most enigmatic and poorly known turtles; there are few observations from the wild and its life history remains virtually unstudied. The species is a moderate-sized (carapace length to $278 \mathrm{~mm}$ ), semi-aquatic omnivorous turtle, that lays one or occasionally two large eggs in each clutch. First purchased from local people in Gorontalo in northern Sulawesi during the late 1980s, large numbers appeared in the commercial turtle trade to China in the early 1990s, and the species was formally described in 1995 . The species is endemic to the island of Sulawesi (formerly known as Celebes), Indonesia, and believed restricted to the Central, Gorontalo, and North Sulawesi provinces. Owing to its limited geographic distribution and low fecundity, as well as extensive and unsustainable exploitation for the food and pet trade and substantial habitat loss, we regard $L$. yuwono $i$ as a species of grave international conservation concern. Unresolved husbandry problems make captive propagation problematic.

Distribution. - Indonesia. Endemic to Sulawesi, where it occurs in the northwestern portions of the island.

Synonymy. - Geoemyda yuwonoi McCord, Iverson, and Boeadi 1995, Heosemys yuwonoi, Leucocephalon yuwonoi.

SubSPECIES. - None recognized.

StATus. - IUCN 2009 Red List: Critically Endangered (CR A1cd+2cd,C1) (assessed 2000); CITES: Appendix II.

Taxonomy. - Leucocephalon yuwonoi was initially described by McCord et al. (1995) as Geoemyda yuwonoi, the specific epithet being a patronym in honor of Indonesian animal collector Frank Yuwono who obtained the first speci- mens. The holotype (MZB 10295) was reportedly collected by local people near Gorontalo $\left(0^{\circ} 33^{\prime} \mathrm{N} ; 123^{\circ} 05^{\prime} \mathrm{E}\right)$ on the Minahassa Peninsula in northern Sulawesi and purchased by Yuwono (McCord et al. 1995). Fritz and Obst (1996) later

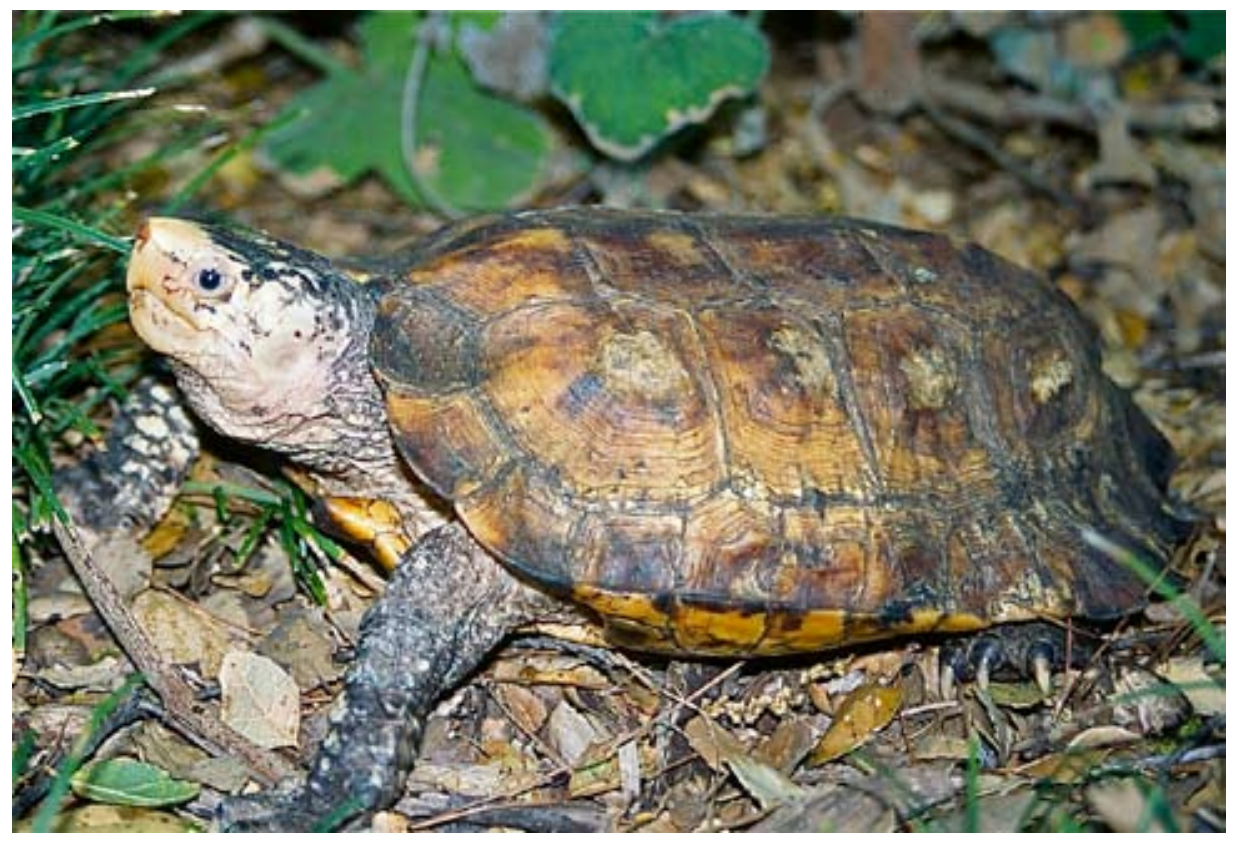

Figure 1. Leucocephalon yuwonoi, adult male from Sulawesi, Indonesia. Photo by Cris Hagen. 


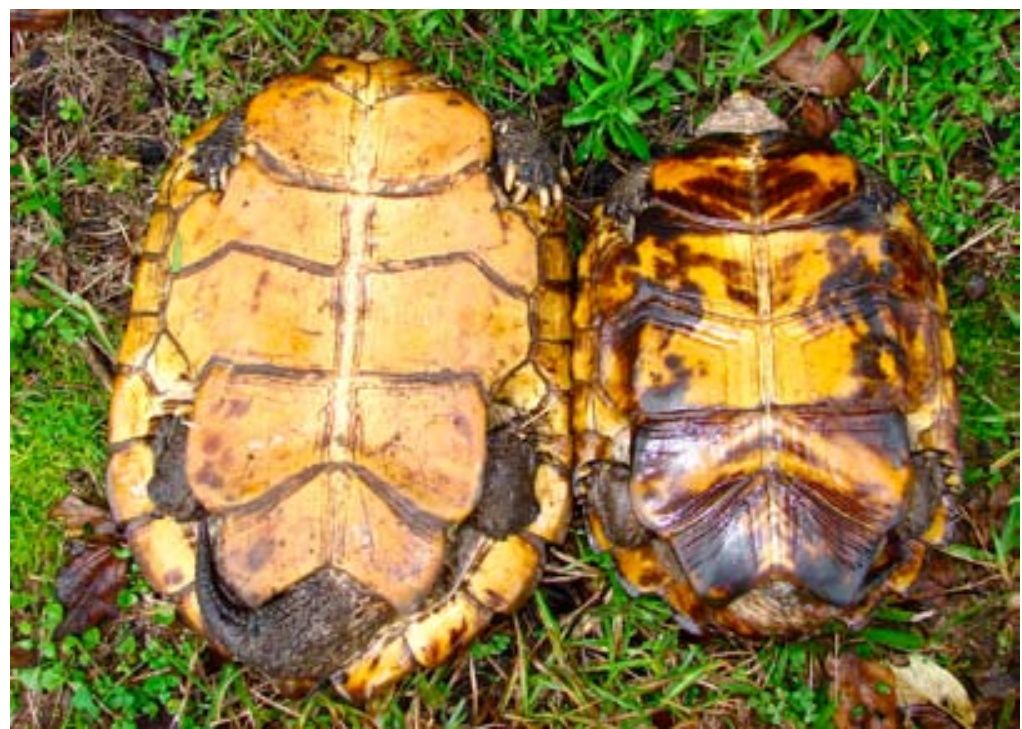

Figure 2. Leucocephalon yuwonoi, adult male (left) and adult female (right) from Sulawesi, Indonesia. Photo by Cris Hagen.

placed both Geoemyda yuwonoi and Geoemyda depressa in the genus Heosemys. However, based on variation in the mitochondrial gene sequence and distinctive morphological characters, McCord et al. (2000) reassigned Heosemys yuwonoi to the new monotypic genus Leucocephalon. Based on mtDNA sequence data, Leucocephalon and Notochelys are sister taxa (Spinks et al. 2004). Further analysis by Spinks et al. (2004) combining mtDNA and nDNA sequence data
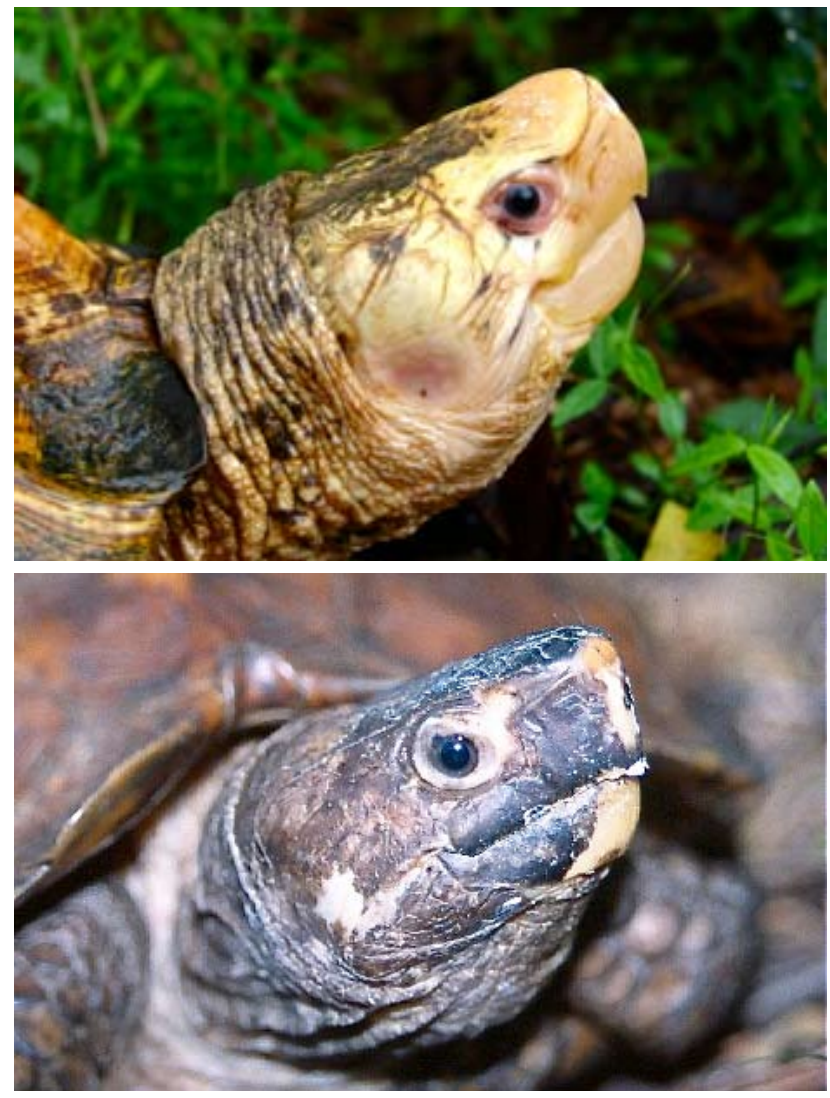

Figure 3. Leucocephalon yuwonoi, adult male (above) and adult female (below) from Sulawesi, Indonesia. Photos by Cris Hagen. found Leucocephalon to be sister to the clade containing Notochelys, Cyclemys, Hieremys, and Heosemys. No subspecies of L. yuwonoi have been described and geographic variation has not been documented.

Description. - Leucocephalon yuwonoi is distinguished from all other geoemydids by a combination of its moderately large size, low, tricarinate, orange-brown carapace, unhinged and unstreaked plastron, short intergular seam (> $50 \%$ of interanal seam length), well-developed bony bridge, distinctive sexually dichromatic head coloration, laterally cusped upper tomium, and lack of a postorbital bar (McCord et al. 1995).

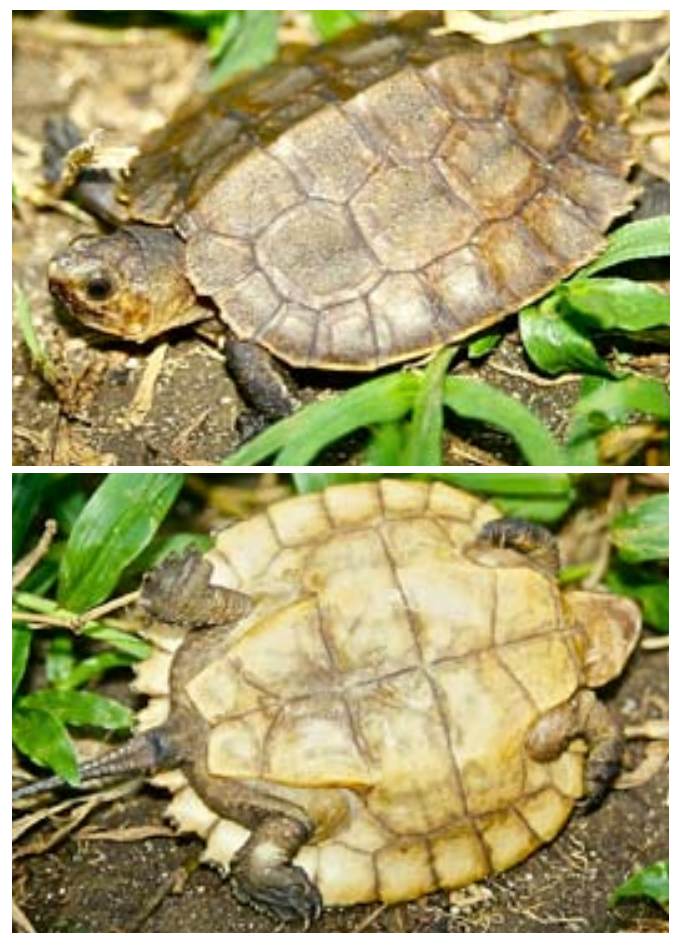

Figure 4. Leucocephalon yuwonoi, hatchling from Donggala County, Cape Santigi, Sulawesi, Indonesia. Photos by Cris Hagen. 


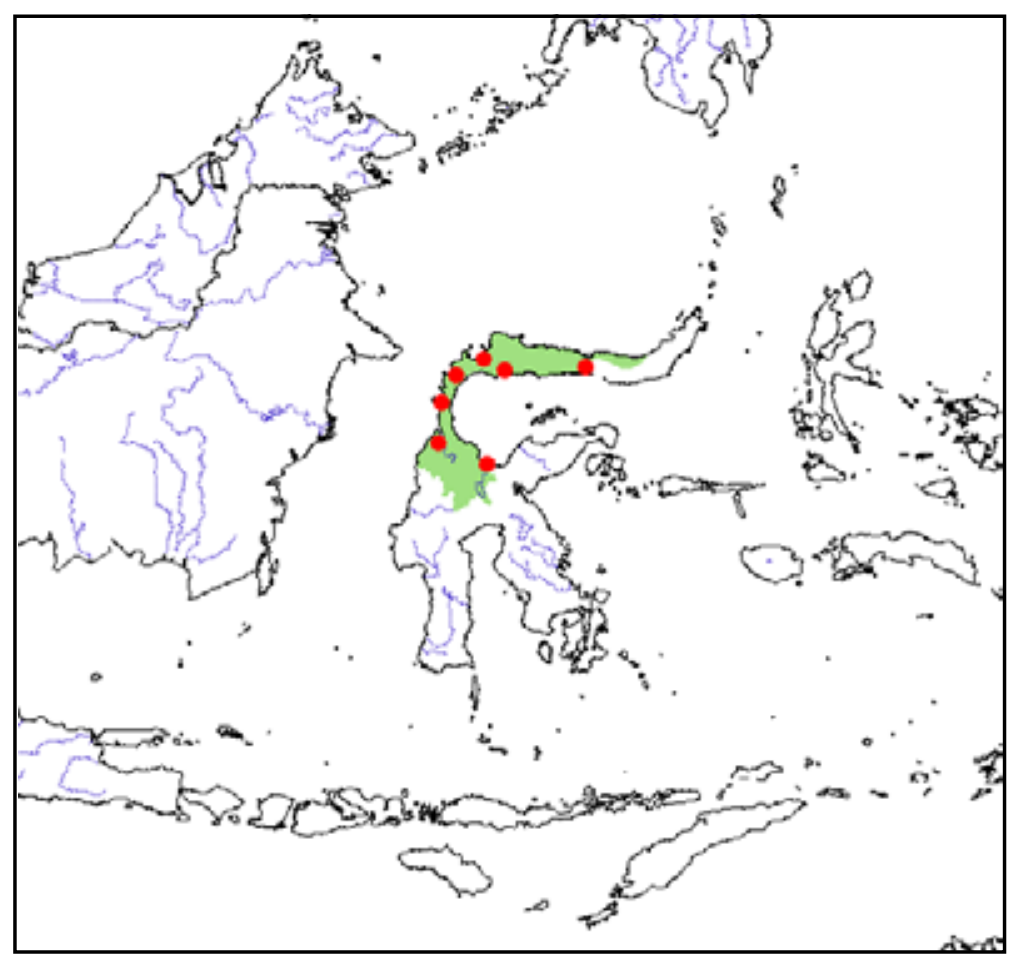

Figure 5. Distribution of Leucocephalon yuwonoi in Sulawesi, Indonesia. Red points = museum and literature occurrence records based on McCord et al. (1995) plus more recent and authors' data; green shading = projected distribution based on GIS-defined hydrologic unit compartments (HUCs) constructed around verified localities and then adding HUCs that connect known point localities in the same watershed or physiographic region, and similar habitats and elevations as verified HUCs (Buhlmann et al., in press), and adjusted based on authors' data.

Leucocephalon yuwonoi is a moderately large geoemydid turtle with a carapace length (CL) to at least $278 \mathrm{~mm}$ in males and $240 \mathrm{~mm}$ in females (Ives et al. 2008). The carapace is elongate, relatively low, moderately tricarinate, widest at the level of marginal (M) 7 or 8 in females and M8 or 9 in males, with a strongly serrated posterior margin and fairly prominent growth annuli. Marginals 9-11 are flared while M12 is much less flared. The lateral margins of M3 through M8 are upturned, forming a shallow dorsal trough. The nuchal scute is small and nearly square. Vertebrals (V) 2 through 5 are wider than long with V1 about as wide as long. Medial and lateral keels are obvious on all scutes (McCord et al. 1995).

The plastron is shorter than the CL, and upturned anteriorly, without a hinge, anchored to the carapace by a solid, moderately long bony bridge. Relatively large axillary and inguinal scutes occur on each bridge. The modal plastral seam formula is interanal $\geq$ interpectoral $\approx$ interabdominal $\geq$ interhumeral $\geq$ interfemoral $>>$ intergular. The plastron is light orange-brown with dark brown and distinctly marked seams. Males have a slightly concave plastron while that of females is flat (McCord et al. 1995).

The head is moderately broad and the upper jaw is slightly hooked in females, and strongly hooked in males. Head coloration is strongly dichromatic. In females, the dorsum and sides of the head are dark brown and slightly mottled with a cream-colored tympanic region. The chin is cream-yellow without obvious dark pigmentation, and the lower tomium is dark brown to black laterally, but with a broad creamy band across the beak area. In males, the posterior dorsum of the head is dark brown, while the anterior dorsum and upper tomium are creamy yellow. The tympanum, much of the side of the head, and chin are whitish to cream. The skin on the posterior dorsum is divided into scales (McCord et al. 1995).

The forearms and manus are relatively large and the anterior surface of the antebrachium in both sexes is covered with five or six rows of large, imbricate scales. Fine scales cover the upper limbs and base of the tail, and post-anally the tail is covered with moderately sized scales. Scales on exposed parts of forelimbs, hindlimbs, and tail are dark brown to almost black. The tail is moderately long, and much longer in males than females. The cloaca is positioned at or beyond the carapacial margin in females and males, respectively (McCord et al. 1995).

Distribution. - Leucocephalon yuwonoi is endemic to the Indonesian island of Sulawesi (previously known as Celebes). The few available field records indicate that it is restricted to areas in the Sulawesi provinces of Central, Gorontalo, and North Sulawesi, occurring from the Santigi region in the north to the area near Lore Lindu National Park in the south (Platt et al. 2001; Hagen and Ching 2005; Riyanto 2006; Ives et al.2008; F. Taula, pers.comm.).Within Central Sulawesi, L. yuwonoi occurs on both the east and west coasts (Riyanto 2006).

Based on anecdotal reports from numerous experienced locals on multiple visits to Sulawesi (Platt and Hagen, pers. obs.), some locality information seems contradictory, and it 
is not clear whether L. yuwonoi is present around Gorontalo and Poso where type specimens were purchased. The presence of individuals in local markets does not necessarily represent locally-collected animals, as traders frequent common sites such as Donggala County and then transport animals to markets throughout the island (Hagen and Ching 2005). However, it is possible that the species is present in these areas but has not yet been detected by biologists in previous surveys.

Habitat and Ecology. - The known habitats of L. yuwonoi are equatorial and experience a wet season extending from October through February with an annual rainfall of 1000 to $3000 \mathrm{~mm}$ (Whitten et al. 1987). Most field observations of $L$. yuwonoi have occurred at night in dense second-growth forest along shallow (30-50 cm deep), clear streams with a moderate gradient and steeply inclined, heavily vegetated banks (Platt et al. 2001; Hagen and Ching 2005). These streams are further characterized by a substrate of pebbles, gravel, and larger stones, with abundant woody debris and occasional rock pools up to $1 \mathrm{~m}$ deep (Platt et al. 2001; Hagen and Ching 2005).

In the vicinity of Bankir along the western coast of Central Sulawesi, L. yuwonoi reportedly inhabits heavily vegetated wetlands bordered by cacao and coconut plantations only a few kilometers from the ocean. These wetlands are typified by clear, shallow water flowing slowly across a substrate of sand, mud, and occasionally rocks; the streamside vegetation consists principally of grasses and herbaceous plants (Riyanto 2006).

According to local turtle collectors, L. yuwonoi is semiaquatic and spends the daylight hours foraging in streamside forest, only entering the water after dark to feed, rest, and possibly mate (Hagen and Ching 2005). Local hunters also stated that turtles are more apt to remain in the forest instead of entering the water during periods of a bright or full moon (Hagen and Ching 2005). The turtles are excellent climbers and tend to flee if approached. If handled, they may scratch, attempt to bite, and void large amounts of feces. Captive specimens spend much time on land and in shallow water (Innis et al. 2002).

Dietary information in the wild is scant, but L.yuwonoi reportedly feeds on insects, leaves, and fallen fruits. The feces of two adults captured by Platt et al. (2001) contained unidentified leaves, four large fruits (possibly Ficus spp.), and eight nematodes of a previously undescribed species (Falcaustra kutcheri; Bursey et al. 2000). Likewise, Riyanto (2006) noted $F$. kutcheri among the feces of five recently captured L. yuwonoi. Insect parts were found in the feces of a juvenile captured by Hagen and Ching (2005). This observation along with reports by local hunters suggest that juveniles may be more carnivorous than adults. Moreover, Hagen and Ching (2005) found fallen fruits (possibly Artocarpus heterophyllus) in a stream inhabited by L. yuwonoi that appeared to bear evidence of feeding by turtles. It is likely that fallen fruits, particularly those of Ficus spp. represent an important food resource for wild L. yuwonoi (Hagen and Ching 2005). At least 73 species of Ficus are known to occur in Sulawesi at densities that are among the highest in Southeast Asia (up to 1163 trees $/ \mathrm{km}^{2}$; Kinnaird et al. 1999). Several species of Ficus bear fruit throughout the year, and figs are especially rich in calcium and magnesium when compared to other fruits in the region. Furthermore, Ficus fruits are believed to be the single most important food resource for frugivorus birds and mammals in Sulawesi (Kinnaird et al. 1999).

Reproduction of L. yuwonoi in the wild has not been reported. Based on observed captive growth rates of wildcaught hatchlings, L. yuwonoi may reach maturity within 7-10 yrs in both males and females. One wild-caught hatchling grew from $60 \mathrm{~mm}$ CL to $200 \mathrm{~mm}$ by 8 yrs old and exhibited obvious female characteristics by $170 \mathrm{~mm}$ and $6 \mathrm{yrs}$ of age (Hagen, unpubl. data). This observation further supports Innis (2003a) and Riyanto (2006) who reported that captive females attain sexual maturity at a CL of ca. $170-180 \mathrm{~mm}$. Another wild-caught juvenile exhibited prominent male sex characteristics by $190 \mathrm{~mm}$. Ontogenetic head color change was observed at a CL of $195 \mathrm{~mm}$ and an approximated $7-8$ yrs of age. The complete change from a brown to a yellowish-white head occurred over a 3-mo time period (Hagen, unpubl. data).

Observations of captive animals suggest that courtship is minimal and males simply overpower females. Receptive females extend their hind legs and elevate the plastron to allow copulation (Innis, pers. obs.). In captivity, females lay one or occasionally two, large hard-shelled eggs in each clutch, and individual females may lay multiple clutches during a single year (Innis 2003a; Riyanto 2006). Innis (2003a) reported the following mean egg dimensions $( \pm 1$ SD) from a sample of 18 eggs: mass $=45.4 \pm 6.0 \mathrm{~g}$; length $=60.8 \pm 6.9 \mathrm{~mm}$; width $=32.4 \pm 2.5 \mathrm{~mm}$. In captivity, females have deposited eggs during every month and the mean internesting interval is 4.6 mo (Innis 2003a; unpubl. data). Females not yet acclimated to captivity generally deposit eggs directly on the surface of the substrate, while well-acclimated females bury eggs in a shallow nest (ca. $4.0 \mathrm{~cm}$ deep; Innis 2003a; unpubl. data).

Little is known about hatchling ecology among wild or captive L. yuwonoi. Two captive-bred hatchlings had CL of 50 and $56 \mathrm{~mm}$, and mass of 33 and $35 \mathrm{~g}$, respectively (Innis, unpubl. data). A single supernumerary vertebral scute was present on the latter, and likewise has been noted in two other captive-bred hatchlings.

Population Status. - Range-wide population surveys for L. yuwonoi have yet to be conducted and its current status is somewhat speculative owing to the paucity of field observations. However, anecdotal evidence suggests that L. yuwonoi still occurs at moderate densities in suitable habitat. Platt et al. (2001) found two adult males along 1 $\mathrm{km}$ of creek bed, and Hagen and Ching (2005) encountered an adult male, two adult females, and a single hatchling during $4.5 \mathrm{hrs}$ of searching approximately $4 \mathrm{~km}$ of another creek. Moreover, local turtle hunters state that five or $\operatorname{six} L$. yuwonoi are often collected from the same stream during a single night of searching. Population trends are difficult to discern given the absence of baseline data, but according 
to local turtle collectors, L. yuwonoi remains common in the Kanggol River and associated tributaries. Interestingly, these commercial hunters claim that repeated collections have been made over the course of several years from the same streams with no apparent diminution in capture rates. Riyanto (2006) reported an average encounter rate of two L. yuwonoi per km of survey transect in Central Sulawesi. Population assessments from elsewhere in Sulawesi are lacking.

Threats to Survival. - Given the restricted distribution and low fecundity of L. yuwonoi, it is likely that widespread collecting for export to food and pet markets (Platt et al. 2001; Hagen and Ching 2005) pose a grave threat to the continued survival of wild populations. Asian trade of $L$. yuwonoi from Indonesia to China peaked at an estimated annual level of 2000-3000 turtles in 1998 and collapsed to about 100 turtles in 1999 (IUCN/SSC Tortoise and Freshwater Turtle Specialist Group and Asian Turtle Trade Working Group 2000). The near-extirpation of source populations is probably responsible for this dramatic decrease in the commercial harvest of L. yuwonoi. Indeed, as Congdon et al. (1993) noted, life history traits of most turtles severely constrain the ability of populations to respond successfully to chronic harvesting, and the concept of sustainable yield is probably not applicable.

Furthermore, habitat destruction probably threatens many populations of L. yuwonoi (Platt et al. 2001; Riyanto 2006). Habitat destruction is attributable to commercial logging, shifting and small-scale plantation agriculture, clearance for large plantations, and transmigration schemes (designed to resettle people from Java to other less populated islands); deforestation rates in Sulawesi are among the highest in the world (Whitten et al. 1987; Myers 1992). It is encouraging to note that L. yuwonoi does not appear solely dependent on undisturbed primary forest. Field observations suggest that if protected from harvesting, $L$. yuwonoi can survive in heavily modified anthropogenic habitats such as second-growth forest, and cacao and coconut plantations (Platt et al. 2001; Hagen and Ching 2005; Riyanto 2006).

Conservation Measures Taken. - Prior to 2002, L. yuwonoi was legally managed by Indonesia as a fisheries resource and not afforded any specific protective status (Samedi and Iskandar 2000). In order to regulate international trade, L. yuwonoi was placed on Appendix II of CITES in 2002, and since 2000 has also been listed as Critically Endangered on the IUCN Red List of Threatened Species (www.iucnredlist.org).

In 2002, Indonesia issued a zero quota for the export of L. yuwonoi. However, some Indonesian exporters still held unused export permits from previous years and were able to export specimens to the United States after the zero quota was imposed (A. Weinberg, pers. comm.). Quotas in subsequent years were set at 100 animals annually and export resumed in 2003. Export quotas were exceeded in 2007 and no trade statistics have been reported for 2008 and 2009 (www.cites.org). Moreover, the actual number traded is probably considerably higher because of the often inadequate species identification skills of wildlife inspectors, the phenotypic resemblance of L. yuwonoi to Cyclemys spp. and Notochelys platynota, and an unquantified illegal trade (Hagen and Ching 2005).

The IUCN Turtle Survival Alliance has established a Taxon Management Group and designated L. yuwonoi as a priority species for conservation initiatives (Innis 2005).

The possible occurrence of L. yuwonoi in any protected area of Sulawesi has yet to be confirmed. The species was included on an online checklist of the reptiles of Lore Lindu National Park (Colijn, cited in Ives et al.2008), but the basis for its inclusion is unclear. To our knowledge, the species has never been collected or observed within the park (Ives 2006; Hagen, unpubl. data). Interviews with local villagers, hunters, and rattan cutters suggest $L$. yuwonoi might inhabit Bogani Nai Wartabone National Park and Panua Nature Reserve, although these reports remain to be verified (Platt 2006; Ives et al. 2008).

Conservation Measures Proposed. - Conservation measures are most effective when based on a thorough understanding of the natural history of a species (Dayton 2003). However, since little is known regarding L. yuwonoi, basic field research on demography, habitat use, diet, and reproduction is urgently needed. As long-term conservation of L.yuwonoi cannot rely solely on habitat conservation, due to current harvesting pressures, conservation of L. yuwonoi will depend on a combination of effective ex-situ and in-situ efforts.

The IUCN Turtle Survival Alliance has proposed establishing a captive assurance colony of L. yuwonoi comprising approximately 100 animals (50 males and 50 females) with the objective of producing offspring for reintroduction to their native habitats should this become necessary. This population would be managed to retain $90 \%$ of the genetic diversity of the founders over the next 100 years (Innis 2005).

Captive propagation of L. yuwonoi should be coupled with in-situ efforts to identify and assess the conservation status of wild populations. Initial surveys should focus on national parks and other protected areas (e.g., Bogani Nai Wartabone and Lore Lindu National Parks, and Panua Nature Reserve) and habitat types (e.g., grass swamps, bamboo forests) where L. yuwonoi is anecdotally reported to occur (Ives et al.2008). Species-specific management plans should be developed and implemented for protected areas found to harbor populations of L. yuwonoi. Ideally, these protected areas could be targeted as refuges for future reestablishment of captive-bred individuals from assurance colonies. Surveys of confirmed localities should be ongoing in order to assess the population status of L.yuwonoi and to further characterize its optimal habitats. Surveys should also assess current and future conservation challenges for the potential of long-term protection for areas of occurrence.

Long-term population monitoring at sites where $L$. yuwonoi is being commercially harvested (Platt et al. 2001; Hagen and Ching 2005; Riyanto 2006) is warranted 
to assess the impact of this off-take on wild populations. This assessment could be further enhanced with more accurate trade statistics and the determination of any significant demographic biases (e.g., sex, body size, source locations) associated with harvested animals. Further, a greater understanding of the varying degrees that the pet, medicinal, and food trades motivate the harvest of $L$. yuwonoi is needed in order to prioritize and recommend market alternatives.

Garnering support by working with local governments to establish priority locations for protection is a critical component for long-term native habitat conservation and support of viable populations. Ultimately, the greatest challenge is in identifying quality habitats for this species where harvest pressures can be alleviated. Until the economics and demand for turtle harvests are sufficiently supplemented, this conflict that has led to these urgent conservation matters could hinder the implementation of conservation action plans.

Captive Husbandry. - Leucocephalon yuwonoi has proven to be a difficult species to maintain in captivity. Small numbers are routinely imported into the United States, Europe, and Japan. Mortality varies widely among keepers and shipments, but generally ranges from 25 to 100\% (Innis et al. 2002). However, several keepers have maintained healthy specimens in captivity since 1998 . At present, approximately 150 adult L. yuwonoi are held in captivity worldwide (Innis, unpubl. data). Ives (2006) found elevated corticosterone levels in a group of long-term captives and suggested that husbandry problems may be due in part to chronic stress.

Innis et al. (2002) recommended that L. yuwonoi be housed in enclosures measuring 1.5 x 1.0 m or larger. Because intraspecific aggression is common in this species, turtles should be housed individually except for brief reproductive introductions. Approximately 50 to $75 \%$ of the enclosure should consist of water 5 to $10 \mathrm{~cm}$ deep. Agitation of the water appears attractive to captives, which preferentially sit in moving water. Enclosures should also include a land area containing both shaded and open areas; the latter is necessary for basking. A sheltered nest box containing slightly damp to dry sphagnum peat is recommended for reproductive females.

Captives are best maintained at an ambient diurnal air temperature of about $28^{\circ} \mathrm{C}$ with nocturnal temperatures dropping to $22^{\circ} \mathrm{C}$. Air temperature of basking spots should be somewhat higher $\left(\mathrm{ca} .32^{\circ} \mathrm{C}\right)$ and a water temperature of $26^{\circ} \mathrm{C}$ is recommended. Humidity in the enclosure should be high (70 to $90 \%)$. A photoperiod of 12 to $14 \mathrm{hrs}$ is believed appropriate for this equatorial species. The importance of ultraviolet light for L. yuwonoi is unknown, but most successful keepers provide some form of ultraviolet light (Innis et al. 2002).

In captivity, L. yuwonoi accepts a wide variety of foods, including strawberries, bananas, leafy greens, figs, cranberries, yellow squash, earthworms, dead mice, goldfish, shrimp, and commercial turtle and tortoise mixtures (Innis et al. 2002). Given the relative lack of data on the natural diet of L.yuwonoi, it is difficult to provide recommendations on the proportions of plant and animal foods to provide to captives. It should be noted that captives are aggressive feeders and poor appetite is usually a cause for concern (Innis et al. 2002).

Captive propagation has proved difficult and to date (2009), only a handful of hatchlings have been produced. The first successful captive breeding occurred in 2003, when a single neonate hatched from an undetected nest constructed in a nest box containing dry sphagnum peat (Innis 2003b). The dam and sire of this hatchling had been in captivity for five years prior to successful reproduction. A second neonate was successfully hatched in 2008 (Innis 2008). This hatchling was produced from an egg deposited $1 \mathrm{~cm}$ deep in a nest box of dry sphagnum, where it was allowed to remain for the duration of the incubation period. Ambient humidity during incubation was 80-90\% and daily temperatures fluctuated between an evening low of $23^{\circ} \mathrm{C}$ and a daytime high of $28^{\circ} \mathrm{C}$. A transverse opaque band appeared on the egg during the first week of incubation, and within one month a blood ring was visible when the egg was candled. Larger blood vessels continued to develop until approximately two weeks prior to hatching when the embryo filled the entire egg. Ten days before hatching a fine crack developed in the eggshell. The egg was then moved to a hatching box containing moist sphagnum and maintained at a constant temperature of $28^{\circ} \mathrm{C}$. Hatching occurred after 176 days of incubation (Innis 2008).

In addition to the two hatchlings described above, at least five hatchlings have been produced in private collections in the United States, and three hatchlings have been produced at the Münster Zoo in Germany, two of which died shortly after hatching (Raffel and Zwartepoorte 2009; Innis, unpubl. data).

Current Research. - We are unaware of any further field studies being conducted on L. yuwonoi at the time of this writing. Basic natural history and ecological studies are urgently needed along with field surveys to determine distribution and population status, particularly to determine whether the species occurs within any protected areas. Moreover, many basic husbandry questions remain to be answered before L. yuwonoi can be successfully propagated in captivity.

Acknowledgments. - Support for Hagen and Platt was provided by the University of Georgia's Savannah River Ecology Laboratory and the Biology Department, Sul Ross State University, respectively. This material is based upon work supported by the Department of Energy under Award Number DE-FC-09-075R22506. An initial draft of this account was improved by the comments of Bose Ikard, Lewis Medlock, and Thomas R. Rainwater. We are grateful to Mike Robinson and the interlibrary loan staff at Sul Ross State University for assistance with obtaining literature. Kimberly Andrews provided helpful comments during the final revisions. 


\section{LITERATURE CITED}

Buhlmann, K.A., Akre, T.S., Iverson, J.B., Karapatakis, D., Mittermeier, R.A., Georges, A., Rhodin, A.G.J., van Dijk, P.P., AND GibBons, J.W. In press. A global analysis of tortoise and freshwater turtle distributions with identification of priority conservation areas. Chelonian Conservation and Biology 8(2): in press.

Bursey, C., Platt, S.G., and Rainwater, T.R. 2000. Falcaustra kutcheri n. sp. (Nematoda: Kathlaniidae) from Leucocephalon yuwonoi (Testudines:Emydidae) from Sulawesi,Indonesia.Journal of Parasitology 86:344-349.

Congdon, J.D., Dunham, A.E., and Van Loben Sels, R.C. 1993. Delayed sexual maturity and demographics of Blanding's turtles (Emydoidea blandingii): Implications for conservation and management of long-lived organisms. Conservation Biology 7:826-833

DAYTON, P.K. 2003. The importance of the natural sciences to conservation. American Naturalist 162:1-13.

FRITZ, U. AND OBST, F.J. 1996. Zur Kenntnis der Celebes-Erdschildkröte, Heosemys yuwonoi (McCord, Iverson, and Boeadi, 1995). Herpetofauna 18:27-34.

Hagen, C. And Ching, I.Y.S. 2005. Distribution, natural history, and exploitation of Leucocephalon yuwonoi in central Sulawesi, Indonesia. Chelonian Conservation and Biology 4:948-951.

InNIS, C.J. 2003a. Preliminary observations on reproductive parameters of the Sulawesi forest turtle (Leucocephalon yuwonoi) in captivity. Chelonian Conservation and Biology 4:720-712.

InNIS, C.J. 2003b. First captive breeding of the Sulawesi forest turtle. Turtle Survival Alliance Newsletter 2003:8.

InNIS, C.J. 2005. Leucocephalon yuwonoi Taxon Management Plan. Unpubl. Report to IUCN/SSC Turtle Survival Alliance, 6 pp.

InNIS, C.J. 2008. Sulawesi forest turtle. Turtle Survival Alliance Newsletter 2008:16-17.

InNIS, C.J., GARner, M., AND RAYMond, J. 2002. Observations on captive husbandry and pathology of the Critically Endangered Sulawesi forest turtle, Leucocephalon yuwonoi. Proceedings 9th Annual Conference of the Association of Reptilian and Amphibian Veterinarians 9:21-26.

IUCN/SSC Tortoise and Freshwater Turtle Specialist Group and Asian Turtle Trade Working Group. 2000. Recommended changes to 1996 IUCN Red List status of Asian turtle species. In: van Dijk, P.P., Stuart, B.L., and Rhodin,A.G.J.(Eds.).Asian Turtle Trade: Proceedings of a Workshop on Conservation and Trade of Freshwater Turtles and Tortoises in Asia. Chelonian Research Monographs No. 2, pp. 156-164.

IVEs, I.E. 2006. Conservation of Sulawesi's two endemic chelonians, Leucocephalon yuwonoi and Indotestudo forstenii; an investigation into in-situ and ex-situ conservation concerns. MSc. Thesis, Antioch New England Graduate School, Keene, New Hampshire.

Ives, I.E., Platt, S.G., Tasirin, J.S., Hunowu, I., Siwu, S., AND RainWATER, T.R. 2008. Field surveys, natural history observations, and comments on the exploitation and conservation of Indotestudo forstenii, Leucocephalon yuwonoi, and Cuora amboinensis in Sulawesi, Indonesia. Chelonian Conservation and Biology 7:240-248.

Kinnaird,M.F.,O'Brien, T.G., ANDSURYAdI,S.1999. The importance of figs to Sulawesi's imperiled wildlife. Tropical Biodiversity 6:5-18.

McCord, W.P., Iverson, J.B., AND BoEADI. 1995. A new batagurid turtle from northern Sulawesi, Indonesia. Chelonian Conservation and Biology 1:311-316.

McCord, W.P., Iverson, J.B., Spinks, P.Q., AND Shaffer, H.B. 2000. A new genus of geoemydid turtle from Asia. Hamadryad 25:86-90.

Myers, N. 1992. The Primary Source: Tropical Forests and our Future. New York: W.W. Norton Co., 416 pp.

Platt, S.G. 2006. A survey to determine the conservation status of endemic chelonians in northern Sulawesi, Indonesia. Bronx, NY: Report to Wildlife Conservation Society, $50 \mathrm{pp}$.

Platt, S.G.,Lee, R.J., and Klemens, M.W.2001. Notes on the distribution, life history, and exploitation of turtles in Sulawesi, Indonesia, with emphasis on Indotestudoforstenii and Leucocephalon yuwonoi. Chelonian Conservation and Biology 4:154-159.

RaFFel, M., AND Zwartepoorte, H. 2009. European turtle breeding reports 2008/2009. Turtle Survival Alliance Newsletter 2009:28-29.

RIYANTO,A. 2006. Notes on exploitation, population status, distribution, and natural history of the Sulawesi forest turtle (Leucocephalon yuwonoi) in north-central Sulawesi, Indonesia. Chelonian Conservation and Biology 5:320-323.

SAMEDI AND IsKandar, D.T. 2000. Freshwater turtle and tortoise conservation and utilization in Indonesia. In: van Dijk, P.P., Stuart, B.L., and Rhodin, A.G.J.(Eds.). Asian Turtle Trade: Proceedings of a Workshop on Conservation and Trade of Freshwater Turtles and Tortoises in Asia. Chelonian Research Monographs No. 2, pp. 106-111.

SPINKs, P., Shaffer, H.B., Iverson, J.B., AND McCord, W.P. 2004. Molecular phylogenetics of the geoemydid turtles. Molecular Phylogenetics and Evolution 32:164-182.

Whitten, A.J., Mustafa, M. and Henderson, G.S. 1987. The Ecology of Sulawesi. Yogyakarta, Indonesia: Gadjah University Press, 777 pp.

\section{Citation Format for this Account:}

Hagen, C.,Platt, S.G., And Innis, C.J.2009. Leucocephalonyuwonoi (McCord, Iverson, and Boeadi 1995) - Sulawesi forest turtle, kura-kura Sulawesi. In: Rhodin, A.G.J., Pritchard, P.C.H., van Dijk, P.P., Saumure, R.A., Buhlmann, K.A., Iverson, J.B., and Mittermeier, R.A. (Eds.). Conservation Biology of Freshwater Turtles and Tortoises: A Compilation Project of the IUCN/SSC Tortoise and Freshwater Turtle Specialist Group. Chelonian Research Monographs No. 5, pp. 039.1-039.7, doi:10.3854/ crm.5.039.yuwonoi.v1.2009, http://www.iucn-tftsg.org/cbftt/. 